\title{
Exploring Mathematical Critical Thinking Skills of Yogyakarta Junior Secondary School Students
}

\author{
Elsa Susanti \\ Yogyakarta State University, Indonesia \\ susanti.elsaa@gmail.com \\ Endah Retnowati \\ Yogyakarta State University, Indonesia \\ e.retno@uny.ac.id
}

\begin{abstract}
This article explores the skills and difficulties in critical thinking of junior Indonesian high school students in mathematics learning. Fifty students of grade IX who were purposive randomly selected from state junior secondary schools in Yogyakarta City were involved as the research subjects. The data were obtained from the test of mathematical critical thinking on the material of geometry. The test consisted of four items that describe each aspect of critical thinking skills, namely interpretation, analysis, evaluation, and inference. The analysis was done by showing the steps of the students 'answers. The result indicated that the average of the aspects of mathematical critical thinking of students were on the high criteria with students' greatest difficulties being in the analysis standard. Meanwhile, the average student success in the interpretation standard was $82 \%$, the standard of the analysis was $46.25 \%$, the evaluation standard was $78.25 \%$, and the inference standard was $77 \%$. Furthermore, from the results of the sample students' exploration answers, it is expected that future teaching should not only focus on fluency in calculation but also on training the students in how to explain the solution steps of the problem solving process as this is important part in critical thinking
\end{abstract}

Keywords: Critical thinking, mathematics

\section{Introduction}

Globalization that brings all of the developments and changes also triggers the competitiveness in every aspect of life. To be able to survive, in all types of careers, good thinking skills that can help people make the right decisions are urgently needed. Basically, these skills are the skills to think critically. Critical thinking involves the process of thinking that is right, systematic, and follows the rules of logic and scientific reasoning. These skills are the basis for a person in communicating ideas, making decisions, analysing, and solving problems (Lau, 2011). Good critical thinking is also the foundation for a person to face reality in a reasonable and independent way (Aizikovitsh-Udi \& Amit, 2011).

Furthermore, critical thinking is a rational and reflective thinking that focuses on deciding what to believe or what to do (Ennis, 2011; Tittle, 2011; Fahim \& Masouleh, 2012). It cannot be denied that in everyday life, people are faced with decisions that require reasoning, understanding, interpretation, analysis, and the evaluation of information. This process involves critical thinking that allows a person to identify problems and assumptions, act ethically, and be able to adapt to changes in a particular environment, and avoid bias and 
prejudice (Lau, 2011; Chukwuyenum, 2013; Tsui, 2017). This is why critical thinking skills are considered to be the main cognitive competencies of the century (Wechsler et al., 2018). Therefore, it is clear that enhancing critical thinking must be the main goal of education (Lau, 2011; Lai, 2011; Sanders, 2016).

More is needed in teaching students the ways of how to think than to devote a lot of effort in teaching them what to think (Tsui, 2017). Students must be challenged to explain what they think and how they think, and to justify their thinking (Pehkonen et al., 2013). Critical thinking is invaluable for the future of students. These skills can be transferred to any appropriate context while growing in complexity along with the user experience. These skills are complicated but important to learn (Carlgren, 2013).

Like the body, the mind has a form of fitness which is reflected in activities carried out in accordance with critical standards (Paul \& Elder, 2006). The standard of this unique type of thinking is like: interpretation which involves expressing or interpreting a problem clearly; analysis which involves analysing relevant or irrelevant statements; evaluation which involves assessing the truth of a statement; and inference which involves making conclusions by considering various perspectives (Gambrill \& Gibbs, 2017; Tsui, 2017; Facione, 2011; Lai, 2011; Tittle, 2011). Emphasizing the standard of critical thinking in learning will facilitate the development of critical thinking itself.

Not only does critical thinking capability make the students become more rational in acting and behaving, but the development of these skills is also an effective way to improve students' understanding of mathematical concepts. Correspondingly, enhancing critical thinking in teaching mathematics in secondary schools is believed to improve the students' performance in mathematics (Chukwuyenum, 2013). Furthermore, the results of Chukwuyenum's research emphasize that the ability to think critically is a factor involved in student success. In particular, high-achievement students have considerable potential to apply these high-level cognitive processes to learning in the classroom (Andersen et al., 2014; Liu et al., 2015).

This study attempts to test this potential by exploring students' critical thinking through a description problem. This type of description problem is in line with what the researchers suggest in designing an assessment of critical thinking skills. This type of description may be more appropriate for assessing critical thinking than multiple choice formats as the steps given by the students are better able to explain their critical thinking constructs (Lai, 2011). By exploring critical thinking, the students are expected to understand their weaknesses and strengths so that they become the basis for developing these skills. This also supports the main goal in the education of gifted students by helping them increase their potential intelligence to a higher level of performance (Altintas \& Sukru, 2012).

\section{Method}

This paper explores the abilities and difficulties in the critical thinking of the students who are from secondary school and assessed as belonging in the high category in mathematics learning. The research subjects were fifty students of grade IX in one of the 
junior high schools assessed as being in the high category in Yogyakarta city based on the results of the 2017 national mathematics examination. The samples were selected through a purposive random sampling technique. The sampling was started by determining the rank of junior secondary schools in Yogyakarta city based on the average of 2016/2017 national mathematics examination scores. Furthermore, the researcher determined the school category and randomly took the samples from the junior secondary school of high category, and finally randomly took the samples from two classes from the school selected as the sample group.

The data were collected through a written test consisting of four descriptive questions on the material of polyhedron. The research instrument was in the form of questions, each of which examines the standard of critical thinking skills, such as interpretation, analysis, evaluation, and inference. This research test instrument was adopted from the other studies that have fulfilled the validity and reliability criteria. (However, this does not guarantee that this test fulfils the validity and reliability criteria for it, just that it imitates tests that are similar). The subjects in this research had studied the material being tested. The student's steps of working on the test are used as a basis for analysing data. Furthermore, the data analysis process was carried out in depth on each question indicator.

\section{Results and Discussion}

In this paper, the researcher collected the information by exploring students' answers from a critical thinking skills test in the field of geometry. Through the four questions (Q1Q4), each of which measures a standard of a particular critical thinking skill, the work of students who were right according to the demands of the question, or correct but incomplete or having something wrong, and wrong or not answering are illustrated in the table below. The errors were found in the students' answers to each question. Most errors were found in the second problem that measures the standard of analysis. Furthermore, the complete results are presented in Table 1.

Table 1

The Answer Results of Diagnostic Test

\begin{tabular}{lccccc}
\hline \multirow{2}{*}{ Kinds of Answer } & \multicolumn{5}{c}{ Amount of Student } \\
\cline { 2 - 6 } & & $\mathrm{Q} 1$ & $\mathrm{Q} 2$ & $\mathrm{Q} 3$ & $\mathrm{Q} 4$ \\
\hline Correct (C) & $f$ & 25 & 2 & 17 & 13 \\
\multirow{2}{*}{ Correct But Incomplete (CBI) } & $\%$ & 50 & 4 & 34 & 26 \\
\multirow{2}{*}{ Incorrect (I) } & $\%$ & 25 & 42 & 32 & 37 \\
& $f$ & 50 & 82 & 64 & 74 \\
& $\%$ & 0 & 14 & 2 & 0 \\
\hline
\end{tabular}

Based on the results of the students' works, the average index of students' critical thinking skills was found to be 70.875 and the results obtained were categorized. The criteria used in categorizing critical thinking skills in this study were formulated in accordance with the basis for categorizing school research samples, i.e. by calculating the average of 
mathematics national examinations of the junior high schools in the Special Region of Yogyakarta Province in 2016/2017 academic year of 59.32 with the standard deviation of 22.95. The categorization and research results found in each category are presented in Table 2.

Table 2

The Criteria and Results of Category

\begin{tabular}{llccc}
\hline \multicolumn{2}{c}{ Categorization criteria } & \multicolumn{3}{c}{ Research results } \\
\hline \multicolumn{1}{c}{ Interval } & Criteria & $\begin{array}{c}\text { Percentage } \\
(\%)\end{array}$ & $\begin{array}{c}\text { Mean } \\
\text { Descriptive }\end{array}$ & Criteria \\
\hline$x \geq 70.795$ & High & 52 & & High \\
$47.845 \leq x<70.795$ & Average & 42 & 70.875 & \\
$x<47.845$ & Low & 6 & & \\
\hline
\end{tabular}

Based on Table 2 above, it can be seen that the average of the students' critical thinking skills is in the high category. This result is in line with the level of students' mathematical skills even though the high score obtained can be said to be still weak because it is only slightly above the high interval.

Furthermore, through exploration of each standard of the critical thinking skills, it was found that students were predominantly weak in analysis with indicators analysing relevant or irrelevant statements. The average ability of students in analysis is in the low category while for the other three standards the average ability of students to succeed is in the high category. The detailed results of each indicator are shown in Table 3 as follows.

Table 3

The Result of Mathematical Critical Thinking Indicators

\begin{tabular}{llcc}
\hline \multicolumn{1}{c}{ Standard } & \multicolumn{1}{c}{ Indicators } & Mean & Criteria \\
\hline $\begin{array}{l}\text { Interpretation } \\
\text { Analysis }\end{array}$ & $\begin{array}{l}\text { Interpret a problem clearly } \\
\text { Analyze relevant or irrelevant } \\
\text { statements }\end{array}$ & 82 & High \\
$\begin{array}{l}\text { Evaluation } \\
\text { Inference }\end{array}$ & $\begin{array}{l}\text { Assess the truth of a statement } \\
\text { Make conclusions by considering } \\
\text { various perspectives }\end{array}$ & 78.25 & How \\
& & 77 & High \\
\hline
\end{tabular}

In addition, the exploration results of students' answers to each standard of critical thinking skills are presented as follows.

\section{Question 1: Interpretation}

In this section, the students were given a problem in which one part of the information needed in solving the problem was not given. The students were asked to determine whether the information available was adequate to solve the problem, otherwise, they were asked to freely add the information and its size and then use it to solve the problem. 
This standard demand is upon how students interpret a problem clearly. Through the analysis of the steps of the students' answer, it is found that most of the students succeeded in adding the information that was lacking with each student giving a different measure so that the conclusion of problem solving was found to be diverse. A student's correct answer form is presented in Figure 1 while a student's wrong answer form is presented in Figure 2.

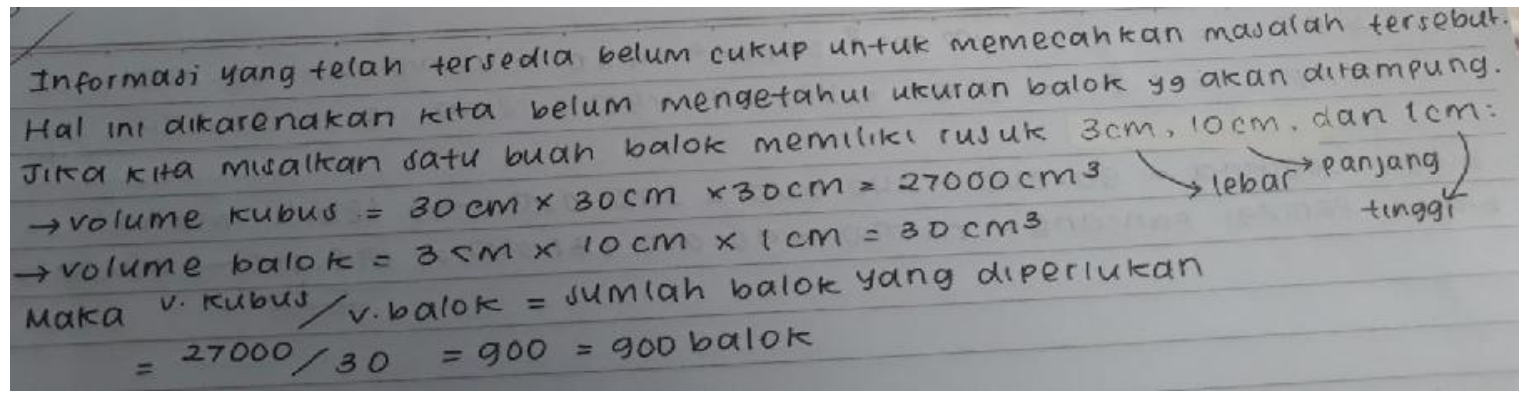

Figure 1. A student's correct answer to the interpretation problem.

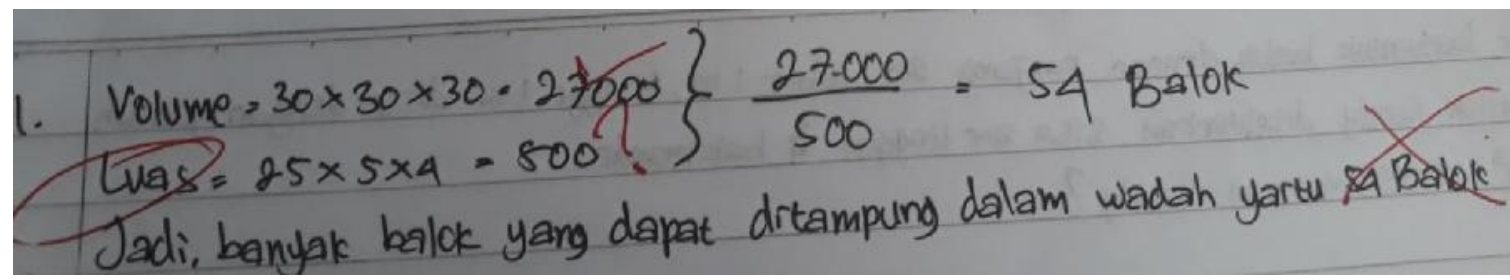

Figure 2. A student's wrong answer to the interpretation problem.

In Figure 1, the student explained that the information available on the problem was not adequate to solve the problem. The student also described the type of additional information needed, then s/he determined the desired size of the information, and used the information appropriately in solving the problem. Meanwhile, in Figure 2, the student did not describe the information that was lacking. S/he was suspected of failing to interpret the problem clearly. Some students were also found to be in the same condition. They were only able to calculate the volume of the cube without being able to interpret the problem using information that was not provided.

\section{Question 2: Analysis}

This standard requires students to analyse whether the cube is included as blocks. This question confused many students. This question may be considered the easiest for students but the results obtained showed the opposite. Predominantly students failed to analyse this statement. Only two students were able to give the correct answer. One of them can be seen in Figure 3 below.

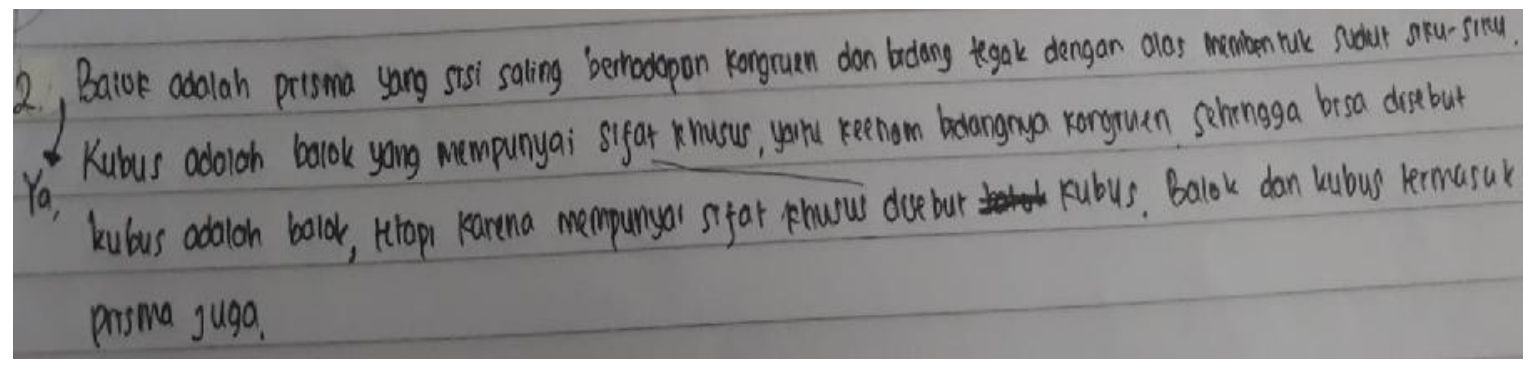

Figure 3. A student's correct answer to the analysis problem. 
The answer presented in Figure 3 by a student who was able to analyse that the cube is a block that has a special property with congruent edges. Meanwhile, most students were only able to see differences in the size of the block and cube sides. This resulted in the analysis conducted by students as being wrong. This does not mean they did not know the elements and the formulas of cube and block. However, they were not able to associate the concepts of geometry. This means that students are predominantly unable to think deeply about the similarity of the concepts of both. Finally, there were many students who were not able to analyse relevant or irrelevant statements. One form of error as described above is illustrated in Figure 4.

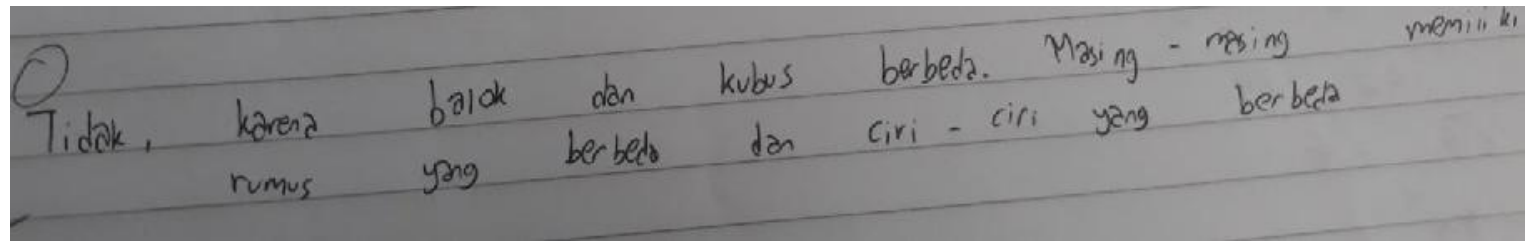

Figure 4. A student's wrong answer to the analysis problem.

\section{Question 3: Evaluation}

In this section, the problem was presented by displaying two different oil containers with different shapes and sizes. In one of the containers, the amount of oil was mentioned. Furthermore, a statement related to the selected container was presented. The students were required to evaluate these choices. The success rate on this problem is quite high, i.e. 78.25. This achievement is probably because the calculation used was quite simple. If students understand the steps to resolve this problem then they successfully evaluated the statement. One of the correct student answers is presented in Figure 5. Meanwhile, a wrong answer is presented in Figure 6.

In Figure 5, the student started the evaluation step by calculating each of the two volumes of the container, then equalized the volume to litres, and finally compared the volume of the selected container with lots of oil to be poured and mentioned the best container choice that should be chosen.

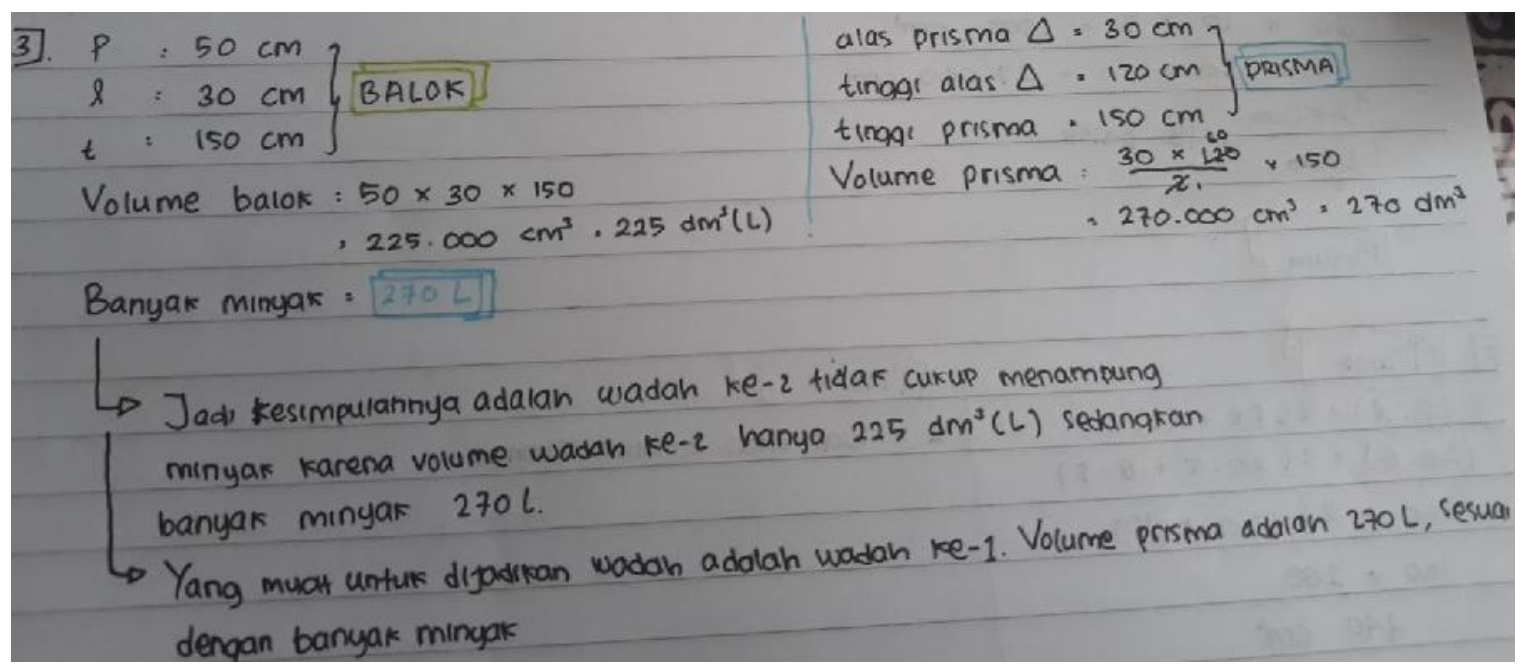

Figure 5. A student's correct answer to the evaluation problem. 


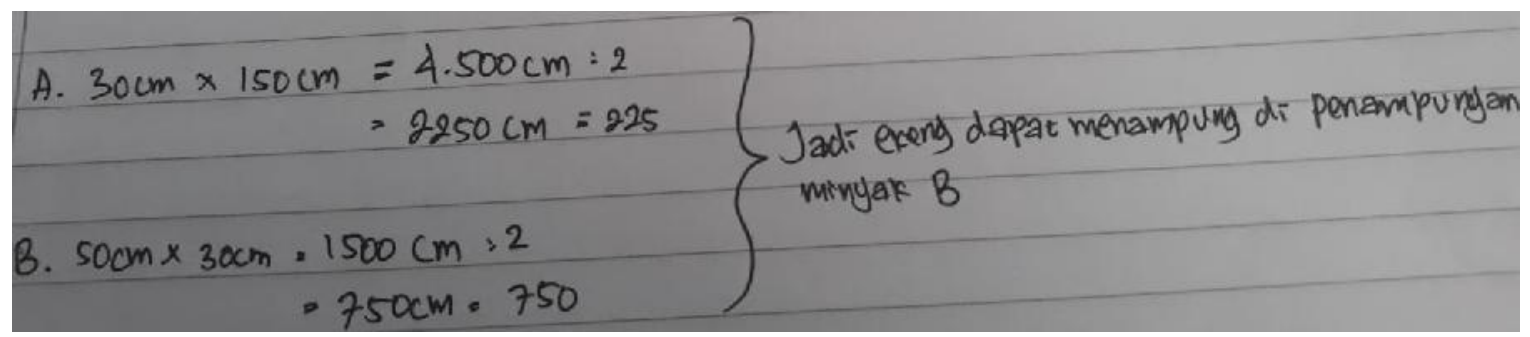

Figure 6. A student's wrong answer to the evaluation problem.

Meanwhile, in Figure 6, the student failed to evaluate the statement because s/he did not understand the concept of completion so the calculation is wrong. The same thing happened to several other students.

\section{Question 4: Inference}

In this standard, the students are required to draw conclusions about the volume of pyramid through changes in height. More than half of students were able to calculate the initial volume and volume of changes in the pyramid, but many of them failed in drawing the final conclusions. One of the correct student answers in this section is presented in Figure 7, while the answers of one of the students who experienced errors is presented in Figure 8.

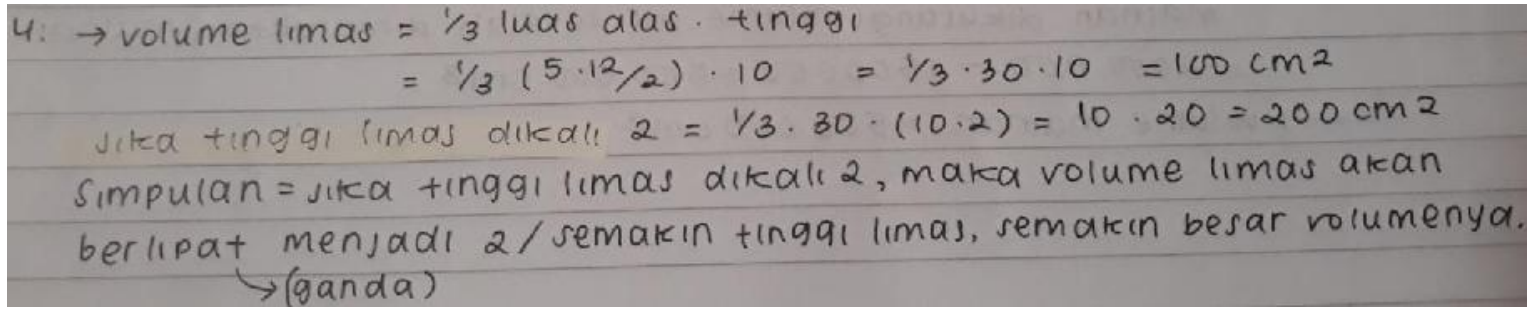

Figure 7. A student's correct answer to the inference problem.

In Figure 7, the student succeeded in calculating the initial volume of the pyramid, the pyramid's volume if its height is multiplied by two, and the student was able to make the conclusion that if the height of the pyramid is doubled then the volume of pyramid also has doubled.

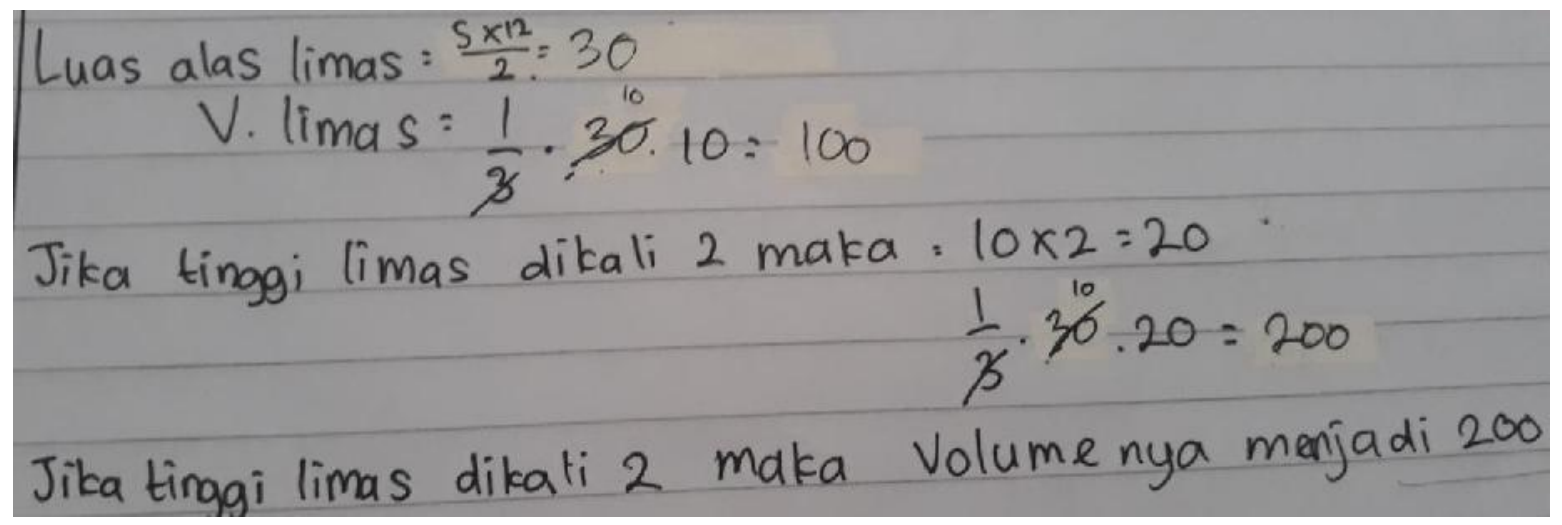

Figure 8. A student's wrong answer to the inference problem. 
Meanwhile, in Figure 8, a student had been able to do the calculation correctly both in calculating the initial volume and the volume after experiencing the height change. However, the conclusion drawn by the students was not yet general. The student drew the conclusion by involving numbers without being able to write it in a correct sentence.

\section{What is obtained and what should be done?}

It should be stated that due to the nature of the sample used, the results and findings of this study apply only to this school and may not be generalised to a wider cohort, although they certainly can provide motivation to teachers in similar schools to conduct similar research.

Through the exploration that has been carried out with each indicator of critical thinking skills, it was found that, in general, the students' critical thinking skills were in line with the level of students' mathematical skills. Research subjects had a high average level of critical thinking skills, although it was not significantly high. The results of this study are quite in accordance with the theory that has been discussed earlier. Critical thinking that is classified as in the high category is thought to be supported because research subjects have a strong basic knowledge so that it was easier to find solutions to the problems they faced (Carlgren, 2013). In addition, motivation for achievement is also believed to be a strong predictor of the success in the level of critical thinking skills in learning (Liu et al., 2015). Finally, it can be concluded that the level of mathematical skills supported the critical thinking skills as expected.

One of the approaches in assessing whether the students really understood the concept being taught was by asking them to explain a number of patterns, so that they engaged with the critical thinking skills (Su et al., 2016). Furthermore, it was also suggested that learning should not only focus on success in calculation but the students also need to be trained in explaining their solutions and to provide logical reasons (Carlgren, 2013). Assessment in learning also needs to involve an analysis process so that it supports students' critical thinking, especially in the analysis standards that require more attention. It should be noted that the main thing in this study was how students think through the mathematics instead of just memorizing formulas ( $\mathrm{Su}$ et al., 2016). The success of education requires consistent training in developing one's thinking skills. Exploration activities on certain abilities need to be done by the teacher as a basis for planning the teaching and learning process. Teachers are expected to continue to find ways to make students want to and tend to think critically (Fahim \& Masouleh, 2012). This is an expectation that could be understood by teachers so that learning is able to facilitate students in increasing their potential intelligence to a higher level of performance.

\section{Conclusion}

Based on the research results, it can be concluded for students in the sample that those secondary school students with a high category of mathematical skills also have a quite high level of critical thinking skills. This is in line with the high level of mathematics achievement so that the results obtained support the existing theory. Most of the students are weak in the 
analysis standard. Meanwhile, in the other standards, the students were able to demonstrate a relatively high level of critical thinking skills. Furthermore, from the results of the exploration of students' answers, it is expected that future teaching should not only focus on success in calculation but also upon training the students in the skills of explaining the solutions that they deliver, especially in emphasizing the analysis of relevant or irrelevant statements.

Due to the sample limitations of this study, the findings can only apply to the students in the sample and cannot be regarded as representing a wider group of Indonesia students. However, the finding can be of interest to teachers and educators in making comparisons with their own situation.

\section{References}

Aizikovitsh-Udi, E., \& Amit, M. (2011). Developing the skills of critical and creative thinking by probability teaching. Procedia - Social and Behavioral Sciences, 15, 10871091. https://doi.org/10.1016/j.sbspro.2011.03.243

Altintas, E., \& Sukru, A. (2012). The effect of teaching with the mathematics activity based on purdue model on critical thinking skills and mathematics problem solving attitudes of gifted and non-gifted students, Procedia - Social and Behavioral Sciences, 46(2012), 853-857. https://doi.org/10.1016/j.sbspro.2012.05.212. https://doi.org/10.1016/j.sbspro.2012.05.212

Andersen, L., Cross, T. L., Andersen, L., \& Cross, T. L. (2014). Are Students With High Ability in Math More Motivated in Math and Science Than Other Students? Are Students With High Ability in Math More Motivated in Math and Science Than Other Students Roeper Review, 36(4), 221-234. https://doi.org/10.1080/02783193.2014.945221

Carlgren, T. (2013). Communication, Critical Thinking, Problem Solving: A Suggested Course for All High School Students,. Interchange, 44(1-2), 63-81. https://doi.org/10.1007/s10780-013-9197-8

Chukwuyenum, A. N. (2013). Impact of Critical thinking on Performance in Mathematics among Senior Secondary School Students in Lagos State, IOSR Journal of Research \& Method in Education, 3(5), 18-25.

Ennis, R. H. (2011). The Nature of Critical Thinking: An Outline of Critical Thinking Dispositions. A Presentation at Sixth International Conference on Thinking at MIT. 1-8. http://faculty.ed.uiuc.edu/rhennis

Facione, P. A. (2011). Critical Thinking: What It Is and Why It Counts. ). Critical thinking: What it is and why it counts. Millbrae, CA: Measured Reasons and The California Academic Press.

Fahim, M., \& Masouleh, N. S. (2012). Critical Thinking in Higher Education: A Pedagogical Look. Theory and Practice in Language Studies, 2(7), 1370-1375. https://doi.org/10.4304/tpls.2.7.1370-1375

Gambrill, E., \& Gibbs, L. (2017). Critical Thinking for Helping Professionals (Fourth ed.). United States of America: Oxford University Press. 
Lai, E. R. (2011). Critical Thinking: A Literature Review Research Report, (June). ?????.

Lau, J. Y. F. (2011). An Introduction to Critical Thinking and Creativity: Think More, Think Better. Hoboken: John Wiley \& Sons, Inc. https://doi.org/10.15713/ins.mmj.3

Liu, Z. K., He, J., \& Li, B. (2015). Critical and creative thinking as learning processes at topranking Chinese middle schools: possibilities and required improvements. High Ability Studies, 26(1), 139-152. https://doi.org/10.1080/13598139.2015.1015501

Paul, R., \& Elder, L. (2006). Critical Thinking: The nature of critical and creative thought. Journal of Developmental Education, 30(2), 34-35.

Pehkonen, E., Näveri, L., \& Laine, A. (2013). On Teaching Problem Solving in School Mathematics, CEPS Journal, 3(4), 9-23.

Sanders, S. (2016). Critical and creative thinkers in mathematics classrooms. Journal of Student Engagement: Education Matters, 6(1), 19-27.

Su, H. F. H. "Angie," Ricci, F. A., \& Mnatsakanian, M. (2016). Mathematical Teaching Strategies: Pathways to Critical Thinking and Metacognition. International Journal of Research in Education and Science, 2(1), 190-200. https://doi.org/10.21890/ijres.57796

Tittle, P. (2011). Critical Thinking: An Appeal to Reason. New York: Routledge.

Tsui, L. (2017). Fostering Critical Thinking through Effective Pedagogy Fostering Critical Thinking Through Effective Pedagogy Evidence from Four Institutional Case Studies, Journal of Higher Education, 73(6), 740-763.

Wechsler, S. M., Saiz, C., Rivas, S. F., Vendramini, C. M. M., Almeida, L. S., Mundim, M. C., \& Franco, A. (2018). Creative and critical thinking: Independent or overlapping components? Thinking Skills and Creativity, 27, 114-122. https://doi.org/10.1016/j.tsc.2017.12.003 